\title{
Seroepidemiological study of visceral leishmaniasis and cattle as a possible reservoir host at Trishal Upazila in Bangladesh
}

\author{
S. Akter, M. Z. Alam, M. T. Islam ${ }^{1}$ and M. M. H. Mondal \\ Department of Parasitology and ${ }^{1}$ Department of Medicine, Bangladesh Agricultural University, Bangladesh \\ Agricultural University, Mymensingh-2202, Bangladesh. E-mail: sajhumur_bau@yahoo.com
}

\begin{abstract}
To study the effect of months, seasons, age and sex on visceral leishmaniasis (VL) in human, data were collected during March 2010 through February 2011 from the register book of Upazila Health Complex (UHC) of Trishal, which is an endemic region for VL in the Mymensingh district. Besides, 70 blood samples were collected from suspected VL human patients to compare microscopy with rK39 immunochromatographic strip test. Additionally, 50 cattle blood samples were also collected from houses with active or recently-treated VL patients to determine the possible animal reservoir of VL through rK39 strip test. Of the suspected VL patients in the UHC registered book, 43.8\% were seropositive. The percentages of seropositive cases were higher in September $(73.3 \%)$, November $(67.2 \%)$ and August (65.5\%) than in May (18.5\%), June (27.5\%) and March (36.7\%). The rainy season (58.4\%) and the winter season $(50.6 \%)$ showed higher seropositive than the summer $(30.7 \%)$ season which was significant $(p \leq 0.001)$. Hospital cases of $V L$ were significantly $(p \leq 0.05)$ higher in $3-14$ years $(49.3 \%)$ and $15-45$ years $(43.5 \%)$ than in children $<3$ years $(32.1 \%)$ and adults aged $>45$ years $(33.6 \%)$ people. The estimated sensitivity of rK39 strip test and microscopic examination were $100 \%$ and $58.8 \%$, respectively and the specificity were $72 \%$ and $100 \%$, respectively. Only two cattle blood samples were found positive to rK39 strip test. Our present study indicates that rK39 strip test is superior to the diagnosis of VL compared with parasitological confirmation by direct microscopy of the peripheral blood. Further works are needed to focus on molecular approaches for diagnosis and epidemiological study of VL, sand flies investigation and to confirm the cattle as animal reservoir for $\mathrm{VL}$ transmission.
\end{abstract}

Keywords: Visceral leishmaniasis, Epidemiology, rK39 strip test, Reservoir host, Trishal

\section{Introduction}

Visceral leishmaniasis is the most severe form of leishmaniasis and if left untreated, is usually fatal (Reithinger and Dujardin, 2007). Leishmania donovani complex (Leishmania donovani and Leishmania infantum) is the etiologic agent of $\mathrm{VL}$ or kala-azar (KA) which is characterized by prolonged fever, weight loss, hepatosplenomegaly, and pancytopenia (Jeronimo et al., 2006). The World Health Organization estimated an incidence of 500,000 VL cases per year, $90 \%$ of which occurs in developing countries like India, Nepal, Sudan, Bangladesh, and Brazil (Desjeux, 2004). Visceral leishmaniasis is an endemic disease of great public health importance in some rural communities in Bangladesh. Bangladesh experiences 40,000 to 45,000 cases yearly, with the total population at risk being around 20 million (Bern and Chowdhury, 2006). Mymensingh district accounts for more than $50 \%$ of the cases in Bangladesh (Bern and Chowdhury, 2006).

The laboratory diagnosis of $V L$ is based on microscopic examination, culture, serological tests, and molecular methods. Field diagnosis of $V L$ involves an immunochromatographic strip test (ICT) that detects immunoglobulin G (IgG) antibody to recombinant K39 (rk39), an antigen expressed by leishmanial species that produce VL. rK39 immunochromatographic strip test used with blood or serum proved sensitive (range, 99 to 100\%) and specific (range, 95 to 100\%) for the noninvasive serodiagnosis of VL in India (Sundar et al., 2005). The rK39 dipstick is a rapid test for VL with very high sensitivity and moderately high specificity (Chappuis et al., 2003).

In South Asia, the disease is transmitted by the female sand fly Phlebotomus argentipes and humans are considered as the only reservoir of VL. Sand fly blood meal analysis in India confirms that Phlebotomus argentipes feed predominantly on bovines and depend on humans' blood as their second choice (Mukhopadhyay and Chakravarty (1987). As cattle are the preferred host for $P$. argentipes, the sand fly vector of $\mathrm{VL}$ in the Indian subcontinent, cattle may act as reservoir of $\mathrm{VL}$. Although there are reports of $\mathrm{VL}$ in Bangladesh (Bern et al., 2007) but the epidemiology of $\mathrm{VL}$ and the possible role of cattle for VL transmission has not been studied in Bangladesh so far. 
The microscopic examination is still considered as gold standard for the diagnosis of VL especially in the areas of endemicity (Reithinger and Dujardin, 2007). The commonly used method for diagnosing VL has been the demonstration of parasites in splenic or bone marrow aspirate. Although the sensitivity of the bone marrow smear and splenic aspirate are about 60 to $85 \%$ and $95 \%$, respectively, but collection of bone marrow is very much painful for the patients and splenic aspirate collection may be associated with fatal hemorrhage. These techniques require invasive procedures, which are difficult to use in large epidemiological surveys and difficult to repeat for follow-up of patients with the disease (Sundar and Rai, 2002). However, microscopy of peripheral blood is less invasive and it requires no special equipment and it is very easy to collect one drop of blood for preparation of microscopic slides.

Therefore, the present study was aimed with the objectives to perform a retrospective study with the epidemiological data of VL in suspected patients, to compare microscopy with rK39 strip test for the diagnosis of $V L$ in human, and to investigate cattle as animal reservoir of $V L$ in Trishal Upazila of Mymensingh district which is the most endemic area of VL in Bangladesh.

\section{Materials and Methods}

\section{Study area}

The study was done at the Trishal Upazila of the Mymensingh district. The data about the VL patients were collected from the register book of Upazila Health Complex (UHC) of Trishal. Human blood was collected from pathology laboratory of UHC. Cattle blood was collected from some active or recentlytreated VL patients' house of Rampur union of Trishal upazila which were identified from the records of UHC Trishal. The parasitological examination was conducted in the laboratory of Parasitology, Bangladesh Agricultural University, Mymensingh.

\section{Collection of data from UHC, Trishal}

From March 2010 to February 2011, 826 suspected VL patients with one or more symptoms like fever for >2weeks, anemia, hepatomegaly, splenomegaly and who were referred by physicians to the pathology laboratory of UHC for VL diagnosis by rK39 strip test were recorded with their sex, age, etc. The whole period of data collection was divided into three seasons such as summer (March/2010-June/2010), rainy (July/2010-october/2010) and winter (November/2010-February/2011).

\section{Collection of blood from human and performing rK39 strip test}

Two to three drops of finger prick blood was taken from 70 suspected VL patients. One to two drops of blood followed by one or two drops of buffer solution provided with the test kit (Chase buffer solution) were placed on the absorbent pad at the bottom of the strip (In Bios kala-azar detect ${ }^{\mathrm{TM}}$ rapid test, USA) and then observed for 8-10 minutes. In the positive cases, there were two bands, a control band and a positive test band appeared within 5 minutes. In few cases, positive band also appeared after 5 minutes (Fig. 1). Only the control band appeared in negative cases (Bern et al., 2000).

\section{Preparation of microscopic slides and examination of slides for the presence of amastigotes}

Immediately after collection of blood from human, two thin smears were prepared for each sample. To prepare a thin smear a small drop of blood was placed on a clean, dry, grease free glass slide and applied even pressure with the help of another even edged glass slide. Then the smears were air dried and fixed with absolute methyl alcohol for 5 minutes and air dried. Afterwards, the smears were stained with Giemsa's stain and air dried (Cable, 1957). The slides were then examined under microscope at high magnification $(100 \times)$. 


\section{Collection of blood from cattle and performing rK39 strip test}

Blood samples were collected from 50 cattle by puncturing the jugular vein with the help of syringe and needle. About $0.5-1 \mathrm{ml}$ blood was taken and one drop of blood followed by one or two drops of buffer were placed on the absorbent pad at the bottom of the strip and waited for 10 minutes for observing the band.

\section{Statistical analysis}

Statistical analyses were carried out by using Statistical Package for Social Science (SPSS) software version, 13.0 (Coakes et al., 2006). Z test for proportions was done to find out the significant differences in the seroprevalence of $V L$ in human in terms of seasons and age. Chi-square test was also performed to test whether there existed any significant effect of sex on the seroprevalence of VL in human. A $p$ value of $\leq 0.01$ or $\leq 0.05$ was considered as significant.

\section{Results and Discussion}

\section{Seroprevalence of $\mathrm{VL}$ in human}

The percentage of seropositive cases of VL in suspected patients from March 2010 to February 2011 were found $43.8 \%$ (Fig. 3) which supported the findings of El-Masum et al. (1995) who reported that seropositivity rate of $\mathrm{VL}$ ranged from $43.6 \%$ to $79.6 \%$ in different subdistricts of Bangladesh. Begum et al. (2002) also reported that $44.9 \%$ cases were seropositive among $9111 \mathrm{VL}$ suspects from 39 endemic areas of Bangladesh. Slightly higher percentage of seropositive cases were observed by Zijlotra et al. (1991) who reported 51\% VL among 132 suspected cases in Southern Sudan. The possible reasons for the variations in this study from the previous findings might be due to differences in the geographical locations of study areas.

\section{Monthly and seasonal seroprevalence of $\mathrm{VL}$}

In the present study, the higher rate of infection was observed in September $(73.3 \%)$ followed by November (67.2\%) and August (65.5\%) and lowest infection was recorded in May (18.5\%) followed by June $(27.5 \%)$ and March (36.7\%) (Fig. 4). Somewhat similar observations were found in the previous study by Bern et al. (2005) who reported that more cases of VL occurred from July-September and fewer cases from January-March in Fulbaria Thana of Mymensingh district in Bangladesh.

The proportion of VL was significantly higher in the rainy $(58.4 \%)$ and winter $(50.6 \%)$ season than the summer (30.7\%) (Table 1) in the present study. Rukunuzzaman and Rahman (2008) found that the rainy season was significantly associated with $\mathrm{VL}(60 \%)$ and carried 2.4 times greater risk of developing VL than other seasons $(p<0.05, O R=2.4)$. Ashkan and Rahim (2008) reported the seasonal variations with more cases presenting in late winter, spring and fewer in summer in southwest Iran. The highest percentage in rainy season may be due to high humidity, heavy rainfall and mostly due to the abundance of vectors because annual rainfall appeared to be the most important predictive variable affecting both the probability of presence and incidence of the disease and rainfall may affect the vector and reservoir hosts by affecting the vegetation, the temperature, and the relative humidity. The lower prevalence rate during summer may be due to the strong protective effect of bed net use in March-June.

\section{Age related seroprevalence of VL}

The present study demonstrated a significant association between $\mathrm{VL}$ and different age groups. Percentages of VL were higher in 3-14 years (49.3\%) and $15-45$ years $(43.5 \%)$ than in children <3 years $(32.1 \%)$ and adults aged $>45$ years $(33.6 \%)$ (Table 2 ) which almost is supported by the findings of Bern et al. (2005) who reported that the risk of kala-azar was highest for people in the 3- to 14-year and 15- to 45year age groups in Bangladesh. In a retrospective analysis of 965 patients worldwide, researchers found that $85.7 \%$ VL cases were diagnosed in young adulthood (age 20-40 years) (WHO, 2000). Davies and Gavgani (1999) observed a declining seroprevalence with advancing age and suggested that cellmediated immunity was associated with a reduction in the seroconversion rate and an increase in the serorecovery rate. 
Table 1. Seasonal seroprevalence of VL

\begin{tabular}{|l|c|c|c|}
\hline \multicolumn{1}{|c|}{ Season } & $\begin{array}{c}\text { No. of rK39 strip } \\
\text { tests }\end{array}$ & $\begin{array}{c}\text { No. of positive } \\
\text { tests }\end{array}$ & $\begin{array}{c}\text { Prevalence } \\
(\%)\end{array}$ \\
\hline Summer (March/2010-June/2010) & 368 & 113 & $30.7^{\mathrm{a}}$ \\
\hline Rainy (July/2010-October/2010) & 219 & 128 & $58.4^{\mathrm{b}}$ \\
\hline Winter (November/2010-February/2011) & 239 & 121 & $50.6^{\mathrm{b}}$ \\
\hline
\end{tabular}

Values with different letters within a column differ significantly at $p \leq 0.001$

Table 2. Age related seroprevalence of VL

\begin{tabular}{|c|c|c|c|}
\hline Age groups & No. of rK39 strip tests & No. of positive tests & $\begin{array}{c}\text { Prevalence } \\
(\%)\end{array}$ \\
\hline$<3$ & 28 & 9 & $32.1^{\mathrm{a}}$ \\
\hline $3-14$ & 300 & 148 & $49.3^{\mathrm{b}}$ \\
\hline $15-45$ & 379 & 165 & $43.5^{\mathrm{ab}}$ \\
\hline$>45$ & 119 & 40 & $33.6^{\mathrm{a}}$ \\
\hline
\end{tabular}

Values with different letters within a column differ significantly at $p \leq 0.05$

\section{Sex related seroprevalence of VL}

No significant difference was seen between the sexes in the present retrospective study. The percentage of VL was $44.6 \%$ in the female and $43.2 \%$ in the male (Table 3 ), which is almost similar and in agreement to the previous report of Rijal et al. (2006) in Nepal. In many studies it has been found that the disease is more common among male than the female (Masum et al., 1990; Talukder et al., 2003). In one explanation, women are sicker longer and die more often from the disease which may be due to women ignored the illness, deemed themselves powerless, women's lower status within the household. Moreover, the economic necessity gives priority of treatment seeking where children and income earners came before women.

Table 3. Sex related seroprevalence of VL

\begin{tabular}{|c|c|c|c|c|c|}
\hline Sex & $\begin{array}{c}\text { No. of rK39 } \\
\text { strip tests }\end{array}$ & $\begin{array}{c}\text { No. of positive } \\
\text { tests }\end{array}$ & $\begin{array}{c}\text { Prevalence } \\
(\%)\end{array}$ & $\begin{array}{c}\text { Chi-square } \\
\text { value }\end{array}$ & $\begin{array}{c}\text { Level of } \\
\text { significance }\end{array}$ \\
\cline { 1 - 4 } Male & 449 & 194 & 43.2 & \multirow{2}{*}{0.153} & NS \\
\hline Female & 377 & 168 & 44.6 & \\
\hline
\end{tabular}

NS=Non significant

\section{Comparison between rK39 strip test and microscopic examination for the diagnosis of VL}

According to rK39 strip test, 34 (48.6\%) of 70 blood samples were positive and the estimated sensitivity and specificity of the rK39 strip test compared to microscopic test were $100 \%$ and $72 \%$, respectively (Table 4). Under microscope, Leishmania amastigotes appeared as round or oval bodies measuring 2 to $3 \mu \mathrm{m}$ in length and were found intracellularly in monocytes and macrophages as described by Sundar and Rai (2002) (Fig. 2). The result of microscopic examination was positive in 20 (28.6\%) and the sensitivity and specificity were $58.8 \%$ and $100 \%$, respectively compared to rK39 strip test (Table 4). Similar study was conducted by Ozerdem et al. (2009) who reported a sensitivity of $41.3 \%$ for rK39 dipstick test according to PCR while it was $90.9 \%$ to microscopic examination and specificity was $100 \%$ and $94.8 \%$, respectively, the sensitivity of microscopic examination according to rK39 dipstick test and PCR was $76 \%$ and $34.5 \%$, and specificity was $97.2 \%$ and $100 \%$, respectively. Some researchers found that sensitivity 
and specificity of rK39 dipstick test ranged from $92 \%$ to $100 \%$ (Veeken et al., 2003) and from $59 \%$ to 97.9\% (Veeken et al. ,2003; Fissore et al., 2004), respectively. These observations suggest a regional limitation of the use of the rK39 test. There is limited research relating to the microscopic examination of peripheral blood for the diagnosis of VL. The sensitivity of microscopic examination of blood is low because of low parasite burden in the peripheral blood (Delgado et al., 1998).

Table 4. Comparative results between rK39 strip test and microscopic examination

\begin{tabular}{|c|c|c|c|c|c|}
\hline Diagnostic assay & $\begin{array}{c}\text { No. of positive } \\
\text { samples }\end{array}$ & $\begin{array}{c}\text { No. of negative } \\
\text { samples }\end{array}$ & $\%$ of positive & Sensitivity & Specificity \\
\hline $\begin{array}{c}\text { rK39 strip test } \\
n=70\end{array}$ & 34 & 36 & 48.6 & 100 & 72 \\
\hline $\begin{array}{c}\text { Microscopic } \\
\text { examination } \\
n=70\end{array}$ & 20 & 50 & 28.6 & 58.8 & 100 \\
\hline
\end{tabular}

\section{Examination of cattle blood with rK39 immunochromatographic strip test}

In the current study, 50 cattle blood samples were also examined with rK39 strip test and two samples (4.0\%) gave positive band. Bhattarai et al. (2010) found Leishmania infections among persons (6.1\%), cows $(5 \%)$, buffaloes $(4 \%)$, and goats $(16 \%)$ by using PCR. There is no available data about the investigation of domestic cattle to identify them as reservoir host of VL in Bangladesh. As the rK39 strip test is not a confirmatory test to identify active case, more sensitive and reliable molecular method such as PCR is to be suggested to identify the parasitic DNA.

In conclusions, the present study supports the view that rK39 immunochromatographic strip test is superior to the diagnosis of VL compared to parasitological confirmation by direct microscopy of peripheral blood. Furthermore, our present study addresses several key epidemiological questions for VL in Trishal, Mymensingh and thus, creating a basis for further epidemiological investigation. Research work focused on molecular approaches (PCR, DNA sequencing) for diagnosis and epidemiological study of $\mathrm{VL}$, the vector fly and to confirm the cattle as animal reservoir for $\mathrm{VL}$ transmission is warranted.

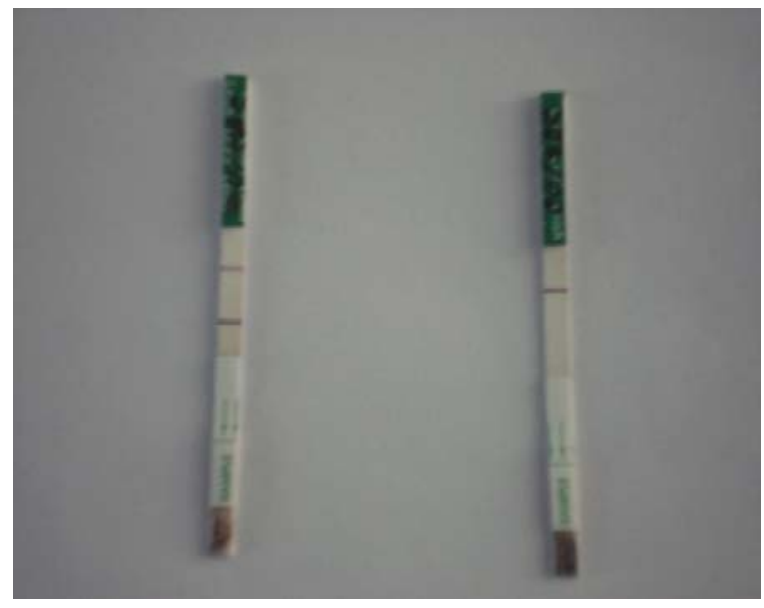

Fig. 1. rK39 strip test results (left one showing double band that reflects positive result and right one shows only control band means negative result)

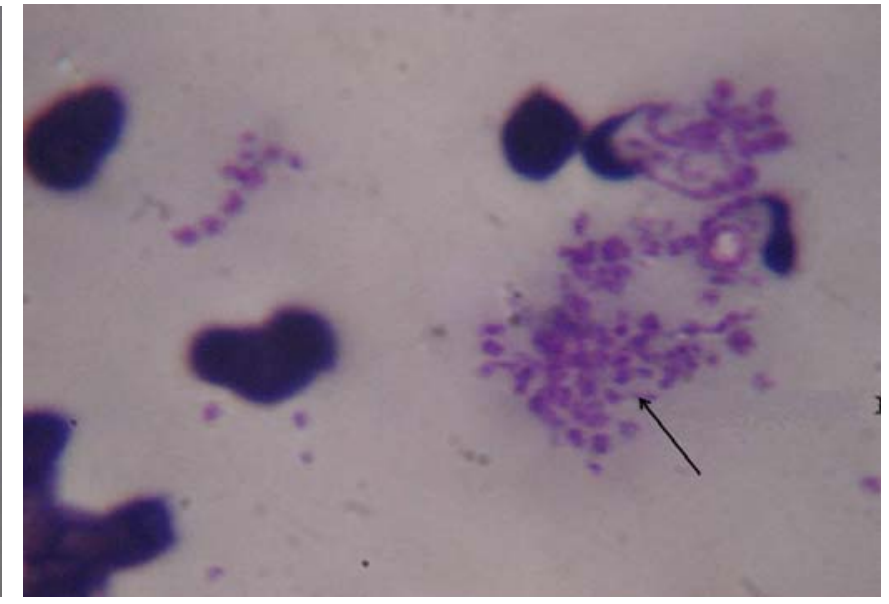

Fig. 2. Amastigote cluster in Giemsa's stained blood smear 


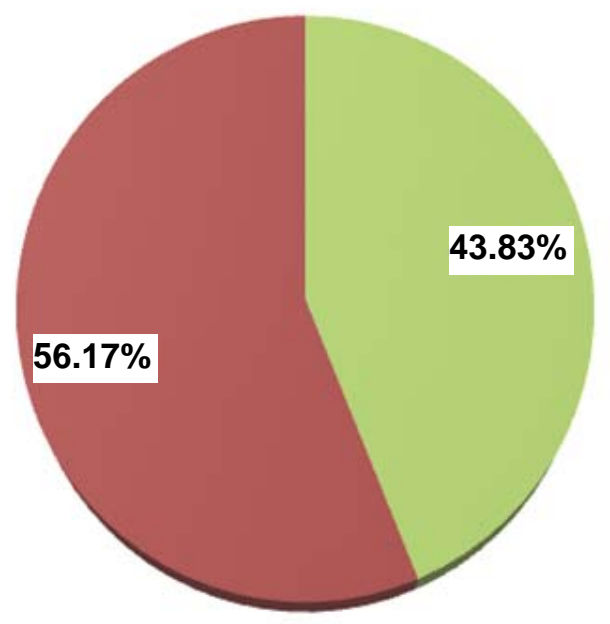

\section{Infected}

non-infected

Fig. 3. Overall seroprevalence of VL

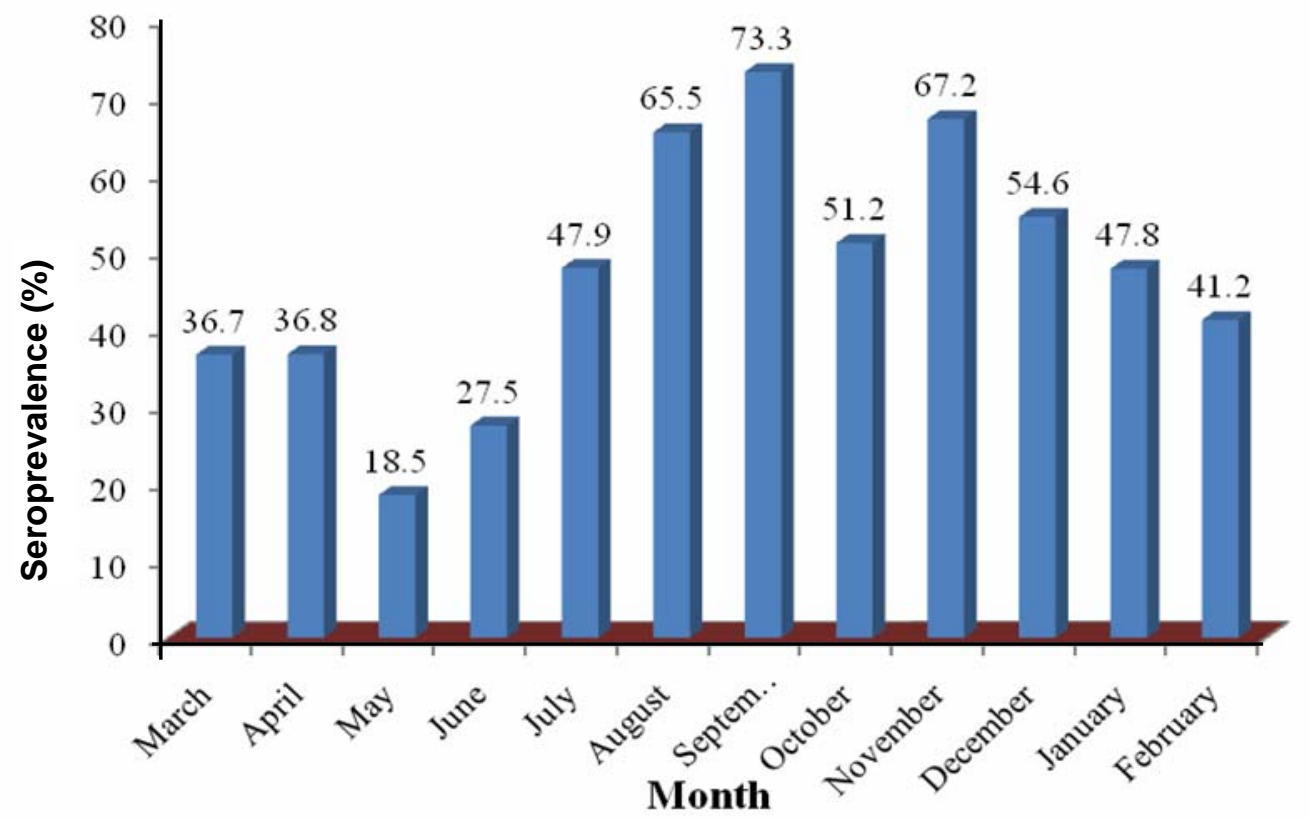

Fig. 4. Monthly seroprevalence of VL

\section{Acknowledgement}

The authors are very much thankful to the staff of the pathology laboratory of the Upazilla Health Complex of Trishal, Mymensingh for their kind help during collection of data and human blood samples. The authors are also grateful to Ministry of Science and Information and Communication Technology for providing financial support to conduct the research work through awarding Shirin Akter for National Science and Information and Communication Technology (NSICT) Fellowship (2010-2011). 


\section{References}

Ashkan, M.M. and Rahim, K.M. 2008. Visceral leishmanisis in paediatrics: a study of 367 cases in southwest Iran. Tropical Doctor , 38(3): 186-188.

Begum, N., Masum, M.A., Mamoon, A.A. and Begum, A. 2002. Visceral leishmaniasis in suspected febrile patients. Bangladesh Journal of Medicine, 13:21-25.

Bern, C., Hightower, A.W., Chowdhury, R., Ali, M., Amann, J., Wagatsuma, Y., Haque, R., Kurkjian, K., Vaz, L.E., Begum, M., Akter, T., Sossah, C.B.C., Ahluwalia, I.B., Dotson, E., Secor, W.E., Breiman, R.F., and Maguire, J.H. 2005. Risk Factors for Kala-Azar in Bangladesh. Emerging Infectious Diseases, 11(5): 655-662.

Bern, C., Jha, S.N., Joshi, A.B., Thakur, G.D. and Bista, M.B. 2000. Use of the recombinant K39 dipstick test and the direct agglutination test in a setting endemic for visceral leishmaniasis in Nepal. American Journal of Tropical Medicine and Hygiene, 63(3, 4):153-157.

Bern, C., Haque, R., Chowdhury, R., Ali, M. and Kurkjian, K.M. 2007. The epidemiology of visceral leishmaniasis and asymptomatic leishmanial infection in a highly endemic Bangladeshi village. American Journal of Tropical Medicine and Hygiene, 76 : 909-914.

Bern, C. and Chowdhury, R. 2006. The epidemiology of visceral leishmaniasis in Bangladesh: prospects for improved control. Indian Journal of Medical Research, 123: 275-288.

Bhattarai, N.R., Auwera, G.V., Rijal, S., Picado, A., Speybroeck, N., Khanal, B., Doncker, S., Das, M.L., Ostyn, B., Davies, C., Coosemans, M., Berkvens, D., Boelaert, M., and Dujardin, J.C. 2010. Domestic Animals and Epidemiology of Visceral Leishmaniasis, Nepal. Emerging Infectious Diseases, 16(2): 231-237.

Cable, R.M. 1957. An Illustrated laboratory Manual of Parasitology. $4^{\text {th }}$ edn, Burgress Publishing Co., Minneapolis, Minnesota, U.S.A., Pp113-114.

Chappuis, F., Rijal, S., Singh, R., Acharya, P., Karki, B.M. and Das, M.L. 2003. Prospective 322 evaluation and comparison of the direct agglutination test and an rK39-antigen-based dipstick test for the diagnosis of suspected kala-azar in Nepal. Tropical Medicine and International Health, 8:277-285.

Coakes, S.J., Steed, L. and Dzidic, P. 2006. SPSS Version 13.0 Windows. John Wiley \& Sons Ltd, Australia.

Davies, C.R. and Gavgani, A.S.M. 1999. Age, acquired immunity and the risk of visceral leishmaniasis: a prospective study in Iran. Parasitology, 119: 247-257.

Delgado, J., Pineda, J.A., Macias, J., Regorda, N.C., Gallardo, J.A., Leal, M., Sanchez-Quijano, A. and Lissen, E. 1998. Low sensitivity of peripheral blood smear for diagnosis of subclinical visceral leishmaniasis in human immunodeficiency virus type 1-infected patients. Journal of Clinical Microbiology, 36(1):315-316.

Desjeux, P. 2004. Leishmaniasis: current situation and new perspectives. Comparative Immunology, Microbiology and Infectious Diseases, 27:305-318.

El-Masum, M.A., Evans, D.A., Minter, D.M. and Harith, A.E. 1995. Visceral leishmaniasis in Bangladesh: the value of DAT as a diagnostic tool. Transactions the Royal Society of Tropical Medicine and Hygiene, 89:185-186.

Fissore, C., Delaunay, P., Ferrua, B., Rosenthal, E., Del Giudice, P., Aufeuvre, J.P., Fichoux, Y.L. and Marty, P. 2004. Convenience of serum for visceral leishmaniasis diagnosis by PCR. Journal of Clinical Microbiology, 42(11):5332-5333.

Jeronimo, S.M.B., de Queiroz Sousa, A. and Pearson, R.D. 2006. Leishmaniasis. In: Guerrant RL, Walker DH, Weller PF, eds. Tropical infectious diseases: principles, pathogens and practice. Edinburgh, Scotland: Churchill Livingstone Elsevier. pp.1095- 1113.

Masum, M.A., Chowdhury, M.S., Ahmed, R.U. and Mia, M.A.H. 1990. Outbreak of visceral leishmaniasis in Thakurgaon, Bangladesh. Jourmal of Preventive Medicine, 4(9): 38-41.

Mukhopadhyay, A.K. and Chakravarty, A.K. 1987. Bloodmeal preference of Phlebotomus argentipes \& Ph. papatasi of north Bihar, India. Indian Journal of Medical Research, 86: 475-480.

Ozerdem, D., Eroglu, F., Genc, A., Demirkazik, M. and Koltas, I.S. 2009. Comparison of microscopic examination, rK39, and PCR for visceral leishmaniasis diagnosis in Turkey. Parasitology Research, 106:197-200.

Reithinger, R. and Dujardin, J.C. 2007. Molecular diagnosis of leishmaniasis: current status and future applications. Journal of Clinical Microbiology, 45(1):21-25.

Rijal, S., Koirala, S., Stuyftb, P.V. and Boelaertb, M. 2006. The economic burden of visceral leishmaniasis for households in Nepal. Transactions of the Royal Society of Tropical Medicine and Hygiene, 100(9):838-841.

Rukunuzzaman, M. and Rahman, M. 2008. Epidemiological study of risk factors related to childhood visceral leishmaniasis. Mymensingh Medical Journal , 17(1):46-50. 
Sundar, S. and Rai, M. 2002. Laboratory diagnosis of visceral leishmaniasis. Clinical and Diagnostic Laboratory Immunology, 9(5): 951-958.

Sundar, S., Maurya, R., Singh, R.K., Bharti, K., Chakravarty, J., Parekh, A., Rai, M., Kumar, K., and Murray, H.W. 2005. Rapid, noninvasive diagnosis of visceral leishmaniasis in India:Comparison of two immunochromatographic strip tests for detection of anti-K39 antibody. Journal of Clinical Microbiology, 44(1):251-253.

Talukder, S.I., Huq, M.H., Rahman, S., Haque, M.A., Sarker, C.B. and Ali, M.S. 2003. Epidemiological characteristics of sixty five cases of Kala-azar attending to a laboratory in Mymensingh. Mymensingh Medical Journal, 12 (2):89-92.

Veeken, H., Ritmeijer, K., Seaman, J. and Davidson, R. 2003. Comparison of an rK39 dipstick rapid test with direct agglutination test and splenic aspiration for the diagnosis. Veterinary Parasitology, 149:139-146.

WHO (World Health Organization), 2000. Leishmaniasis/HIV co-infection.WHO report on global surveillence of epidemic-prone infectious diseases; Chapter 10, and Fact Sheet No. 116.

Zijlotra, E.E., El- Hasan, A.M., El-Toum, L.A., Satti, M.S., Ghalib, H.W., Sondor, E., and Winkler, A. 1991. Kala-azar in displaced people from Southern Sudan: epidemiological, clinical and therapeutic findings. Transactions of the Royal Society of Tropical Medicine and Hygiene, 85:365-369. 